\title{
Is there any relation of urine specific gravity with nail length?
}

\author{
Muhammad Imran Qadir and Hafsa Nawab* \\ Institute of Molecular Biology and Biotechnology, Pakistan \\ *Corresponding author: Hafsa Nawab, Institute of Molecular Biology and Biotechnology, Multan, Pakistan
}

\begin{tabular}{|c|c|}
\hline ARTICLE INFO & ABSTRACT \\
\hline Received: May 05, 2019 & The customary extent of the specific gravity is between 1.010 to 1.030 . The growing \\
\hline Published: 㸷 May 13, 2019 & $\begin{array}{l}\text { express gravity (which mean there is more concentration in the pee condition called hy- } \\
\text { persthenuria) may associated with drying out, emesis, free entrails, over the top sweating, }\end{array}$ \\
\hline $\begin{array}{l}\text { Citation: Muhammad Imran Qadir, } \\
\text { Hafsa Nawab. Is there any relation of } \\
\text { urine specific gravity with nail length?. } \\
\text { Biomed J Sci \& Tech Res 18(1)-2019. } \\
\text { BJSTR. MS.ID.003080. }\end{array}$ & $\begin{array}{l}\text { the surge of blood may less to kidney (as a result of dissatisfaction of heart). In case the } \\
\text { pee explicit gravity more than } 1.035 \text { prompts more absence of hydration. The common } \\
\text { explicit gravity of pee in neonates is } 1.003 \text { and in the hypovolemic affliction pee explicit } \\
\text { gravity is } 1.015 . \text { If an individual has logically explicit gravity on account of parchedness, } \\
\text { by then masters propose to drink progressively more water. Signs related to the nail plate } \\
\text { are commonly apportioned into two sorts supported the adjustment in its life structures }\end{array}$ \\
\hline $\begin{array}{l}\text { Keywords: Urine Specific Gravity; Urine } \\
\text { Test; Nails Length }\end{array}$ & $\begin{array}{l}\text { or the shading. Pale change the nail portrays iron lack while blue recoloring could moreo- } \\
\text { ver be a typical for symptom. Spoon shaped nails that are called Koilonychias are found in } \\
\text { iron inadequacy pallor. If there's loss of edge among nail and nail bed, it's called sign. This } \\
\text { study gave the result that males with urine specific gravity of } 1.01 \text { has longer nails, and } \\
\text { this character is not vibrant in females. }\end{array}$ \\
\hline
\end{tabular}

\section{Introduction}

The customary extent of the specific gravity is between 1.010 to 1.030. The growing express gravity (which mean there is more concentration in the pee condition called hypersthenuria) may associated with drying out, emesis, free entrails, over the top sweating, the surge of blood may less to kidney (as a result of dissatisfaction of heart). In case the pee explicit gravity more than 1.035 prompts more absence of hydration. The common explicit gravity of pee in neonates is 1.003 and in the hypovolemic affliction pee explicit gravity is 1.015 [1-3]. If an individual has logically explicit gravity on account of parchedness, by then masters propose to drink progressively more water. If individual is progressively prepared dried out or not to drink more water, by then masters gives intravenous fluids. In case an individual is overhydrated, by then masters proposes you for more tests and check the causes and outline of results for treatment plan. The masters do many test for pee like urinalysis, pee culture, ketone testing and pee osmolality and their outcomes help authorities to make an accurate investigation. The preliminary of pee explicit gravity accomplice thickness of pee with the thickness of water. A case of pee for the specific gravity test may have 1 to 2 ounces of pee. Nails contain a couple of parts like proximal nail wrinkle, distal end, Lateral nail cover, fingernail skin, Lunular, hyponychial, and structure. Nails improvement all around begins in ninth embryonic week and at sixteenth embryonic week; there are unmistakable nails at the proximal end. Nail plate is confined at its proximal end [4-6].

Nails are imperative inside the distinctive confirmation of the various contaminations in light of trademark sign of a distress is regularly seen over the nail plate. Signs related to the nail plate are commonly apportioned into two sorts supported the adjustment in its life structures or the shading. Pale change the nail portrays iron lack while blue recoloring could moreover be a typical for symptom. Spoon shaped nails that are called Koilonychias are found in iron inadequacy pallor [8,9]. If there's loss of edge among nail and nail bed, it's called sign [7]. It's commonly observed by installing a paper over the nail and scan for any opening between the paper and conjointly the proximal end of nail plate. Symptom is found in various disorders like assimilation diseases, vas ailments and channel ailments. Blood accumulation at a lower place the nail plate that is to boot called chip hemorrhages is generally seen in overpowering cordites. Leukonychia are the white spots at a lower 
place nails that depicts hypoalbuminemia. Space of nails happens in skin condition. So, we tend to are set up to break down sort of contaminations by essentially smart nails. This is consistently why; they're of flooding essentialness unremarkably physical examination (Table 1). The aim of the present research was to connect the urine specific gravity and nail length.

Table 1: Analysis of the specific gravity in urine in male and female.

\begin{tabular}{|c|c|c|c|}
\hline \multicolumn{2}{|c|}{ Male } & \multicolumn{2}{c|}{ Female } \\
\hline Long nail length & $\begin{array}{c}\text { Short nail } \\
\text { length }\end{array}$ & Long nail length & $\begin{array}{c}\text { Short nail } \\
\text { length }\end{array}$ \\
\hline $1.02 \pm 0.0061$ & $1.02 \pm 0.029$ & $6.3 \pm 0.8$ & $1.00 \pm 0.14$ \\
\hline \multicolumn{2}{|c|}{$p$ value 0.33} & \multicolumn{2}{|c|}{$p$ value 0.29} \\
\hline
\end{tabular}

\section{Material and Methods}

Pee test is the direct technique to check your prosperity and test for diseases. One essential worry in the test that by and large checked is express gravity of pee. Before taking a precedent, master may demand that you complete a couple of things that prepared you for a test. As an issue of first significance, pro may demand that you leave taking medications that may irritates your results. The key time for taking a model is at the start of the day when the pee is progressively engaged. The authority will give you a plastic compartment with a top to assemble pee for test in it. You ought to use antibacterial wipe to clear your genital zone to diminish the chances of contamination by microorganisms. By then authorities will send your example in the lab where strip is used to check the component of the pee parts. Strip is dunked in the case for 5 to 10 seconds. In the wake of emptying the strip, it will exhibit to you the changed tints. By then expert complexity it and the shading diagram and uncover to us the results.

\section{Project Design}

We asked subjects whether we are allowed to take their pee tests and assess it for different parameters. We instructed them in regards to the tradition of taking the pee test and after that we accumulated their pee tests in a cleaned plastic compartment. We took pee testing strip and dunked in pee test till end and empower it to make due with 3 to 4 seconds, when express required tints made on strip we composed tones with the reference shading given on holder spread, and afterward we interrogated subjects regarding their nail development and note the data to relate these two parameters. Aggregate of 100 subjects participated in this examination work and they were understudies in Bahauddin Zakariya University, Multan, Pakistan.

\section{Statistical Analysis}

We took the percentages of the urine specific gravity values taken by their urine tests.

\section{Discussion}

Male subjects with explicit gravity of 1.01 demonstrates the quickest nail development which implies that subjects whose pee has explicit gravity of 1.01 has quick nail augmentation yet in females results are not clear in light of the fact that there is little distinction between their rates esteems and we can't discover job of pee explicit gravity in nail development in females.Earlier explores give us learning about the job of blood bunch in nail development and that exploration finishes up the job of blood bunch in nail development and gave the outcomes that nail development is connected with blood gathering. This exploration work job of pee explicit gravity is another examination work and we didn't locate any past work which connected these two factors.

\section{Conclusion}

This study gave the result that males with urine specific gravity of 1.01 has longer nails, and this character is not vibrant in females.

\section{References}

1. Mendelsohn E, Hagopian A, Hoffman K, Butt CM, Lorenzo A, et al. (2016) Nail polish as a source of exposure to triphenyl phosphate. Environment international 86: 45-51.

2. Mendelsohn E, Hagopian A, Hoffman K, Butt CM, Lorenzo A, et al. (2016) Nail polish as a source of exposure to triphenyl phosphate. Environment international 86: 45-51.

3. Qadir MI, Javid A (2018) Awareness about Crohn's Disease in biotechnology students. Glo Adv Res J Med Medical Sci 7(3): 062-064.

4. Qadir MI, Saleem A (2018) Awareness about ischemic heart disease in university biotechnology students. Glo Adv Res J Med Medical Sci 7(3): 059-061.

5. Qadir MI, Ishfaq S (2018) Awareness about hypertension in biology students. Int J Mod Pharma Res 7(2): 08-10.

6. Qadir MI, Mehwish (2018) Awareness about psoriasis disease. Int J Mod Pharma Res 7(2): 17-18.

7. Qadir MI, Shahzad R (2018) Awareness about obesity in postgraduate students of biotechnology. Int J Mod Pharma Res 7(2): 14-16.

8. Qadir MI, Rizvi M (2018) Awareness about thalassemia in post graduate students. MOJ Lymphology \& Phlebology 2(1): 14-16.

9. Qadir MI, Ghalia BA (2018) Awareness survey about colorectal cancer in students of M. Phil Biotechnology at Bahauddin Zakariya University, Multan, Pakistan. Nov Appro in Can Study 1(3). 
ISSN: 2574-1241

DOI: 10.26717/BJSTR.2019.18.003080

Hafsa Nawab. Biomed J Sci \& Tech Res

(c) (P) This work is licensed under Creative

Submission Link: https://biomedres.us/submit-manuscript.php

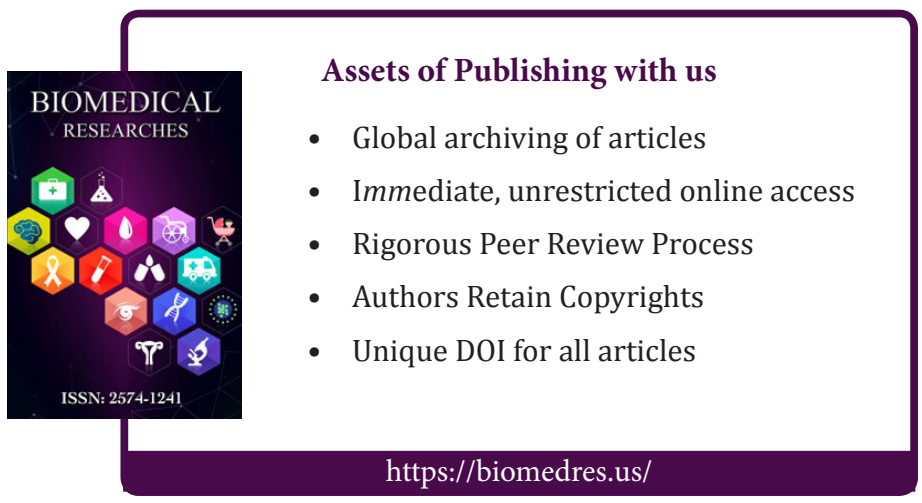

